\title{
Como se faz o género na escola? - uma etnografia
}

\author{
Fazendo género no recreio: a \\ negociação do género em \\ espaço escolar.
}

PEREIRA, Maria do Mar.

Lisboa: Imprensa de Ciências Sociais, 2012.

O livro de Maria do Mar Pereira, fruto de investigação analítica e etnográfica, realizada numa escola de Lisboa, trata-se de uma profunda inovação no quadro dos estudos de género em Portugal e de um sinal inequívoco da maturidade conceptual desta área. A apresentação a que a autora procede no quadro teórico do seu livro deixa claro o seu objectivo de introduzir uma perspectiva performativa na análise do género. Tal bastaria como inovação num país onde, muitas vezes, ainda se pensa (mesmo no plano de investigação publicada) que a perspectiva performativa do género consistiria no seguinte:

[A] leitura errónea [de Gender Trouble] é mais ou menos esta: posso levantar-me de manhã, abrir o armário, olhar lá para dentro, e decidir que género quero ser hoje. Posso tirar uma peça de roupa e mudar o meu género, estilizá-lo e depois, nessa noite, mudá-lo outra vez e ser uma coisa radicalmente diferente. $O$ que resulta desta leitura é uma espécie de comodificação do género, em que escolher um género é uma espécie de ato consumista. [...] A performance do género nunca é totalmente fluida, ela é configurada dentro dos limites discursivos do nosso mundo, e esses limites têm de ser tidos em conta (Butler, citada na p. 51).

O trabalho desenvolvido por Maria do Mar Pereira parece ter sido desenhado para refutar este tipo de interpretação voluntarista do género, profundamente desconhecedora dos quadros teóricos pós-estruturalistas que a perspectiva da performatividade invoca de forma clara. ${ }^{1}$ Assim uma subjetividade nunca é um dado, nunca é simplesmente uma escolha do sujeito. Aliás e como também é sublinhado por Pereira tratase de um processo complexo de negociação com as mesmas normas que tanto nos sexuam, como nos tornam pessoas. Negociar, palavrachave para entender esta proprosta, é, como a autora indica, uma "produção contínua e que nunca está acabada e que exige um trabalho ativo e árduo" (p. 55).

A pesquisa empírica empreendida pela autora leva-a observar o modo como adoles- 
centes vão negociar com as normas de género em termos das interações no quadro do espaço escolar. E aqui a autora mostra mais uma vez as suas credenciais analíticas aliando uma tradição etnometodológica de pesquisa com as perspectivas pós-estruturalistas por via da invocação desta ideia de negociação, conseguindo pôr em prática um projeto que é servido pelas duas principais linhas orientadoras da perspectiva performativa.

Numa perspectiva também ela inovadora em Portugal, apesar de ter tradição nas ciências sociais desde o final dos anos 60 , especialmente na teoria feminista, a autora não desliga a produção das subjetividades genderizadas da produção da máquina simbólica da heterossexualidade hegemónica, tratando-as como um todo significativo.

Neste livro é-nos servida uma etnografia densa, no sentido de Geertz, ${ }^{2}$ aludindo às negociações entre indivíduos, grupos e instituições com o contexto, tendo a autora conseguido darnos, por via da etnografia, a explicitação dos comportamentos e dos discursos no quadro de um contexto que é tornado inteligível para quem lê e é exterior a este. Assim o livro trata de uma etnografia sobre estudantes de uma turma do $8^{\circ}$ ano de escolaridade - a turma $8^{\circ} \mathrm{X}$ da Escola Azul (pseudónimo de uma escola de Lisboa).

Ao confrontarmo-nos com as falas dos e das jovens participantes, entendemos a profunda consciência de que o género está a ser feito, para além de ser evidente que o género corresponde a um padrão normativo através do qual negociamos o nosso comportamento. Diz uma participante no estudo:

\begin{abstract}
Ah, têm de ser... têm de ser homens, têm de ser machos, têm de ser grandes, têm de jogar bem futebol, têm de ser aquilo que a sociedade quer que eles sejam, têm de... essas coisas... Que não é verdade, mas provavelmente na cabeça deles é isso (p. 139).
\end{abstract}

Que melhor descrição para o conceito de normas de géneros nas palavras de uma adolescente?

Igualmente este trabalho tem o mérito de entender o diálogo sempre em mudança entre a semelhança e diferença em homens e mulheres, construindo um exercício de difícil equilíbrio entre a heterogeneidade e a homogeneidade intra-grupo. Conforme nos mostra de forma cabal na sua etnografia, as abordagens exclusivamente centradas na diferença acabam por reforçar o dimorfismo de género, traduzindo uma diferença relativa em absoluta diferença, o que é conforme às normas de género. Por oposição a outras obras sociológicas portuguesas, este livro está mais atento às matizes e nuances que o género na sua fluidez com limites insinua. A autora prefere centrar-se no papel da negociação, o que the permite operar num quadro de pensamento que evita essas armadilhas conceptuais e que the permite dar outro tipo de vocalização às interações observadas e descritas nesta obra. Assim tanto as coordenadas de diferença e semelhança inter-grupo como as coordenadas intra-grupo de homogeneidade e heterogeneidade são evocadas, mas como parte de um jogo complexo, realizado na situação e dentro de um determinado contexto. Assim, em vez de observações tonitruantes sobre a diferença, que muitas vezes não só reproduzem como legitimam o pensamento e discursos sociais, este trabalho pode ser entendido como um esforço em dar outra inteligibilidade aos processos complexos de enunciação do género e das suas expressões.

Igualmente deve ser reconhecida a dimensão participativa deste tipo de inquérito. Afastandose das dicotomias sujeito-objeto, este livro mostra como construir um projeto de investigação empírico participado, oferecendo às pessoas que etnografou possibilidades diferentes de se sentirem integradas na pesquisa, produção de materiais, entrevistas posteriormente discutidas com praticantes e debates sobre a análise realizada. Esta reflexividade é de saudar e mostra a importância das metodologias participativas, ainda pouco usuais na investigação social, e permite reconhecer a estes/as participantes um papel de actores/as sociais.

Este trabalho é um marco nos estudos de género em Portugal, mostrando não apenas o dinamismo da investigação recente sobre a área temática mas a sua maturidade, dado que permite, numa localização transversal às disciplinas, aumentar a reflexividade das mesmas, produzindo conhecimentos que apresentam tanto imaginação epistemológica (pelo modo como diversifica os saberes, modos de análise e de interrogação) como imaginação democrática (pelo modo como produz reconhecimento pelos atores/as sociais e suas práticas). ${ }^{3}$ É pois uma obra que deverá constituir uma referência inovadora na produção sobre género em Portugal e no mundo lusófono, quer pela sua brilhante articulação teórica, quer pelo modo como nos incita a uma aproximação aos e às participantes, quer pela qualidade da análise que evidencia.

\section{Notas}

' João Manuel OLIVEIRA, 2011. 
${ }^{2}$ Clifford GEERTZ, 1973.

${ }^{3}$ Boaventura Santos SANTOS, 2000.

\section{Referências}

GEERTZ, Clifford. The Interpretation of Cultures: Selected Essays. New York: Basic Books, 1973.

OLIVEIRA, João M. "Fazer e desfazer o género: performatividades, normas e epistemologias feministas". In: NEVES, Sofia (Org.). Género e
Ciências Sociais. Maia: Publismai, 2011. p. 49.66 .

SANTOS, Boaventura de Sousa. A crítica da razão indolente: contra o desperdício da experiência. Porto: Afrontamento, 2000.

João Manuel de Oliveira Universidade do Porto 